\title{
Application of dc and mark-space bias differential electrolytic potentiometry for determination of cyanide using a programmable syringe pump
}

\author{
Tawfik A. Saleh • A. M. Abulkibash
}

Received: 1 March 2011/Accepted: 28 July 2011/Published online: 10 August 2011

(C) The Author(s) 2011. This article is published with open access at Springerlink.com

\begin{abstract}
This paper describes a rapid sequential injection titration method for the determination of cyanide in aqueous solutions. Mercuric nitrate was used as a titrant and a pair of gold-amalgam electrodes as an indicating system. The technique of differential electrolytic potentiometry using both mark-space bias (m.s.b.) and dc current for polarization was employed. The optimum values of current and percentage bias were $5 \mu \mathrm{A}$ and $13 \%$, respectively. The effects of dispense time, volume of analyte, supporting electrolyte, and the concentration of titrant were investigated. The results obtained are in agreement with those of the standard method (APHA), with a relative standard deviation of $1.43 \%, t=0.783, F=1.713$. A sampling rate of about 20 samples per hour was achieved with good reproducibility and lower consumption of reagents.
\end{abstract}

Keywords Cyanide $\cdot$ Mercuric nitrate $\cdot$ Syringe pump

\section{Introduction}

Cyanide is used in many industrial applications such as electroplating, precious metal refining, gold mining, metal ore processing, and smelting, chemical and petrochemical applications. Cyanide compounds used in industry include hydrogen cyanide, cyanogen chloride, cyanide salts containing potassium or sodium, gold and silver cyanide. The mining of gold depends on cyanidation (MacArthur et al. 1988). Cyanide leaching, which is one of the gold

T. A. Saleh $(\varangle) \cdot$ A. M. Abulkibash

Chemistry Department, King Fahd University of Petroleum and Minerals, Box 6724, Dhahran 31261, Saudi Arabia

e-mail: tawfikas@hotmail.com; tawfik@kfupm.edu.sa extraction technologies, has replaced the mercury amalgamation. It involves spraying sodium cyanide solution, of a concentration of 200-600 ppm, on piles of ground ore. Gold reacts with cyanide to form a water-soluble compound. Gold then can be extracted by passing the solution over an activated carbon. The remaining cyanide solution is stored in covered ponds (Schnepp 2006).

Methods which are commonly used for the determination of cyanide include titrimetric, colorimetric and ion selective electrodes. Titration of free cyanide with silver nitrate is a traditional method (Clesceri et al. 1995). However, halide species if present will be a source of interference during titration. The colorimetric methods suffer from interferences of the oxidizing agents used or the buffers added. On applying ion selective electrodes (ISE), cyanide is reduced during the addition of both, the buffers and solutions that help in maintaining the ionic strength. Moreover, the membrane itself could be easily damaged or clogged in presence of silver ions. Halides, sulfides, thiocyanate or any other complexing agents used might interfere. ISE method suffers a drawback where it is necessary to perform calibration every hour in order to obtain a $\pm 2 \%$ reproducibility. This reproducibility is limited by factors such as temperature fluctuations, drift and noise. The life of the ISE electrode is generally affected by exposure to higher concentrations of cyanide $\left(>10^{-3} \mathrm{M}\right)$ (Stankovic et al. 1993). Ion chromatography combined with amperometry was applied for the determination of cyanide (Themelis et al. 2009; Johnson and LaCours 1990). Raman and IR spectroscopy, which are expensive techniques, have been used for the detection of cyanide (Lukey et al. 1999; Stuart and Van der Heuvel 1992).

Based on the literature review, cheap, portable equipment and simple method are required to be used for in situ analysis. Here, we reported a method consisting of syringe 
pump and detection unit. The detection unit consists of polarizing identical electrodes connected with a smallstabilized dc current. The potential difference between these electrodes is measured.

\section{Experimental}

Solution preparation

All chemicals used were of analytical grade and doubly distilled water was used throughout. All reagents were prepared and stored in polythene vessels.

1. Mercuric nitrate solution: $1.71 \mathrm{~g}$ of Fluka Mercuric Nitrate, $\mathrm{Hg}\left(\mathrm{NO}_{3}\right)_{2} \cdot \mathrm{H}_{2} \mathrm{O}$ was dissolved in distilled water in the presence of drops of concentrated nitric acid and diluted to $1 \mathrm{~L}$ to give $1,000 \mathrm{ppm}$.

2. Potassium nitrate solution: $10.10 \mathrm{~g}$ of $\mathrm{AnalR} \mathrm{KNO}_{3}$ was dissolved in distilled water and diluted to a $100 \mathrm{~mL}$ standard flask to produce $1 \mathrm{M}$ supporting electrolyte solution.

3. Potassium cyanide: Potassium cyanide was purchased from Fisher Scientific Company. To prepare a cyanide solution of 1,000 ppm, an amount of $0.6250 \mathrm{~g} \mathrm{KCN}$ was dissolved in distilled water and diluted to $250 \mathrm{~mL}$. This solution was used to prepare a series of standard solutions by dilution.

4. Nitric acid solution: $6 \mathrm{M}$ nitric acid was prepared by careful and gradual adding $48.8 \mathrm{~mL}$ of concentrated nitric acid to $51.2 \mathrm{~mL}$ distilled de ionized water.

5. Solutions of interfering species: one thousand parts per million solutions were prepared from solid/liquid stocks (Fisher), which were then diluted as needed.

\section{Apparatus}

The manifold used in this method consists of a programmable syringe pump (PSP) and infinity controller (IC) combined with mark-space bias current source and silver electrodes, as depicted in Fig. 1. PSP and IC are produced by J-KEM Scientific, Inc. This PSP has multi-port distribution valves. Each port can be used for the suction and dispensing the required solution. The syringe handles volumes of $10-50 \mathrm{~mL}$.

\section{Procedure}

Figure 1 illustrates the schematic diagram of the setup employed in this study. The titration was carried out as described in the following steps. In the initial step, the cell and valves were cleaned by aspirating a certain volume of the deionized water, and then dispense. Then, a certain

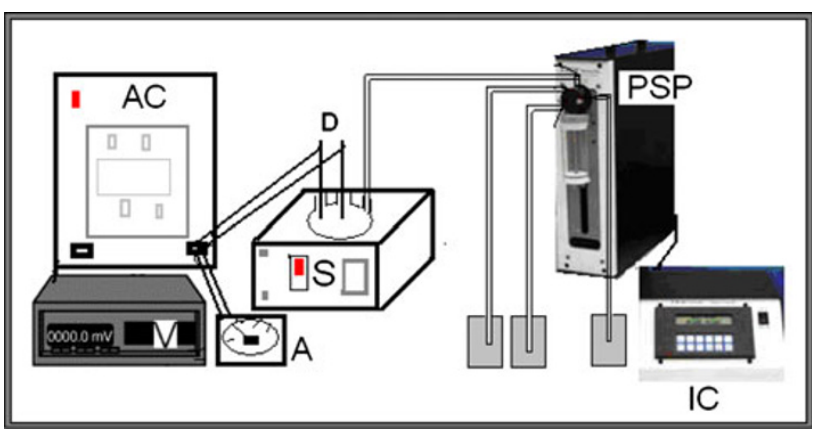

Fig. 1 Scheme of PSP-DEP manifold used; PSP programmable syringe pump, $I C$ infinity controller, $A C$ mark-space bias current source, $A$ micrometer, $D$ electrodes, $S$ stirrer, $V$ voltmeter

volume of the sample was aspirated via the sample valve, and dispense to the cell. Potassium nitrate was then aspirated and dispensed into the cell. A solution of mercuric nitrate was aspirated into the syringe pump and then dispensed to the cell. The volume of mercuric nitrate dispensed was recorded by infinity controller. During the mercuric nitrate dispense, the end-point was determined by measuring the difference in potential. The difference in potential was then plotted against the volume in $\mu \mathrm{L}$. The protocols of the experimental procedure in the proposed sequential injection system were programmed as illustrated in Table 1.

\section{Results and discussion}

\section{Method optimization}

The method was optimized using the uni-variant approach and the best compromise between sensitivity, reproducibility, sampling rate and low consumption of reagents was taken into consideration. The main variables that affect this type of determination are volumes and concentrations of the reagents, the type of electrode polarization. The parameters optimized were current density, type of electrodes, $\%$ bias, concentration of supporting electrolyte, and concentrations of samples and reagents.

\section{Current optimization}

The dc current used to polarize the electrodes was varied between 0.1 and $70 \mu \mathrm{A}$, as presented in Fig. 2. On increasing the current above $10 \mu \mathrm{A}$, the resulting differential peaks become broad and asymmetric. When currents lower than $2.5 \mu \mathrm{A}$ were employed, the heights of the peaks were found to decrease relative to the height of the peak obtained at a current of $5 \mu \mathrm{A}$. When the current more than $5 \mu \mathrm{A}$ was selected, there was no significant 
Table 1 The protocols of the experimental procedure in the proposed method

\begin{tabular}{llcccc}
\hline Step & Action description & Time $(\mathrm{s})$ & $\begin{array}{l}\text { Valve } \\
\text { position }\end{array}$ & $\begin{array}{l}\text { Flow rate } \\
(\mu \mathrm{L} / \mathrm{s})\end{array}$ & $\begin{array}{l}\text { Volume } \\
(\mu \mathrm{L})\end{array}$ \\
\hline 1 & Aspirate cyanide sample & 5 & 2 & 100 & 120 \\
2 & Dispense the sample into the reaction cell & 8 & 1 & 80 & 120 \\
3 & Aspirate potassium nitrate & 12 & 3 & 140 & 500 \\
4 & Dispense the potassium nitrate into the reaction cell & 12 & 1 & 140 & 500 \\
5 & Aspirate mercuric nitrate & 7 & 4 & 100 & 140 \\
6 & Dispense the mercuric nitrate & 90 & 1 & 30 & 140 \\
7 & Aspirate water & 10 & 5 & 140 & 500 \\
8 & Dispense water for cleaning & 10 & 1 & 140 & 500 \\
\hline
\end{tabular}

Fig. 2 Titration of $0.5 \mathrm{~mL}$ of 25 ppm Cyanide using dc current: 70, 30, 20, 10, 5, 2.5, and $1 \mu \mathrm{A}$
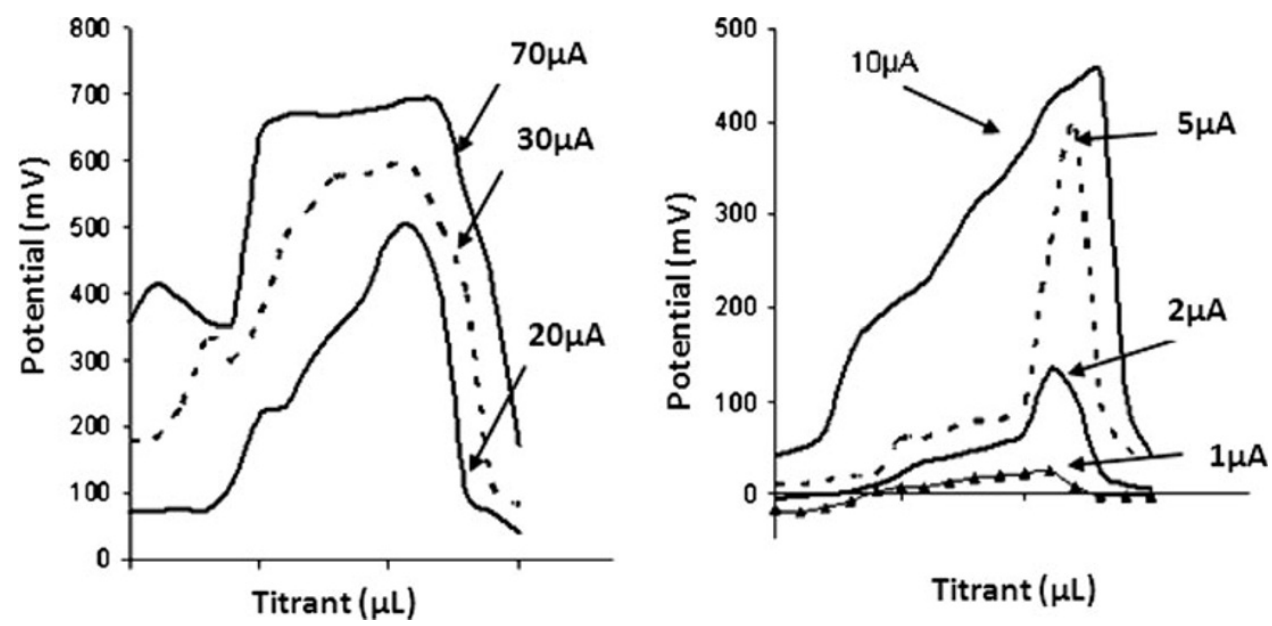

Titrant $(\mu \mathrm{L})$ increase in the height of the peak, however, the peak became asymmetric. Therefore, the $5 \mu \mathrm{A}$ dc current gives a symmetrical peak of a considerable height. Because of this, the value of $5 \mu \mathrm{A}$ was selected as optimum value for the forthcoming work.

Type of electrodes and polarization source

To investigate the behavior of different types of electrodes, several titrations were performed using a pair of each of platinum, gold and silver as an indicating system. The resulting differential curves were poor and of high overpotential. This indicates the sluggish response and abnormal behavior of these electrodes. The resulting titration curves were of no value for the end point location. However, by simply immersing those electrodes in pure mercury, a metal/amalgam was formed and found to improve the titration curves, as depicted in Fig. 3. This is due to the abnormal response of the platinum amalgam, which was reflected, in a serious shift in the end point observed during the course of the titration (Abulkibash et al. 2000, 2003; Al-Ghannam 2004). The behavior of both silver and gold amalgam electrodes were investigated under the same conditions and found to show better reproducibility and less drift. The resulting titration curves are symmetrical sharp and smooth, indicative of normal behavior of these electrodes. It is interesting to note that gold amalgam electrodes were found to equilibrate quickly and give symmetrical peaks with considerable height.

The behavior of these electrodes during their applications in dc and in m.s.b. was investigated. As presented in Fig. 4a, b, comparing with those polarized by dc, the electrodes polarized by m.s.b. equilibrate rapidly and have lower charge transfer over potentials. These electrodes retain their normal response for long periods due to the continual reversing of the signal, which keeps them clean and active. However, titration curve obtained by Pt/amalgam are asymmetric and cannot be used to locate the end point as it can be concluded from Fig. 4c.

\section{Effect of changing the $\%$ bias}

The effect of changing the $\%$ bias on the titration curve was examined by cyanide titration using $\mathrm{Au} / \mathrm{Hg}$ electrodes at different percentages of bias. The resulting titration 

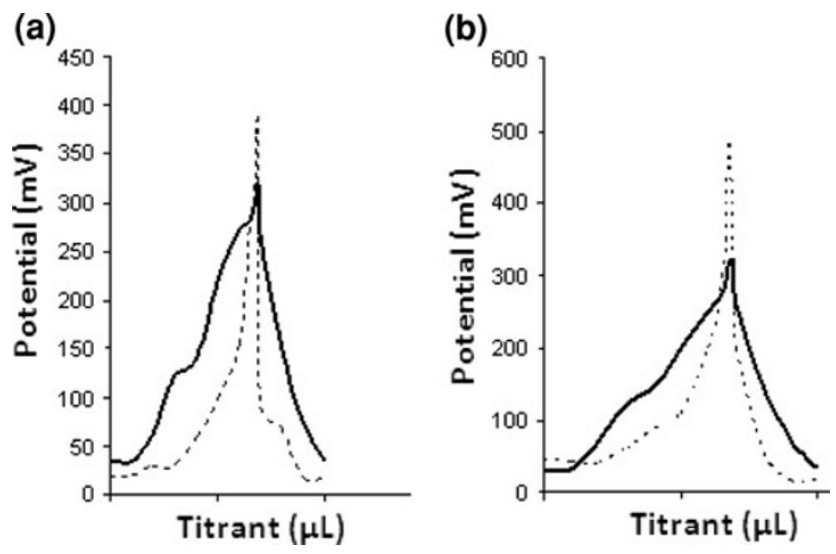

Fig. 3 Titration of $0.5 \mathrm{~mL}$ of $25 \mathrm{ppm}$ Cyanide: using: (a) $\mathrm{Ag} / \mathrm{Hg}$ electrodes (dashed line) and $\mathrm{Ag}$ electrodes (solid line), (b) $\mathrm{Au} / \mathrm{Hg}$ (dashed line) and Au electrodes (solid line)

Fig. 4 Titration of $0.5 \mathrm{~mL}$ of current of $5 \mu \mathrm{A}$ and a percentage bias of 13 . (a) $\mathrm{Ag} /$ $\mathrm{Hg}$ electrodes, (b) $\mathrm{Au} / \mathrm{Hg}$ electrodes (c) $\mathrm{Pt} / \mathrm{Hg}$ electrodes. (dc current: dashed lines; m.s.b. solid lines) 25 ppm Cyanide using dc

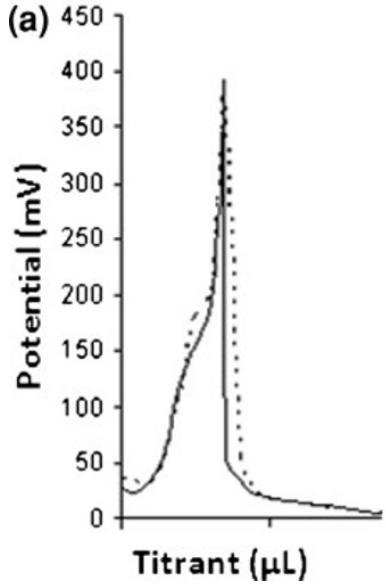

curves obtained at $80 \%$ bias exhibits a high over voltage. This is probably due to the high dc component associated with the ac current. On decreasing the percentage bias to a value of $33 \%$, a similar titration curve was obtained but with less over voltage. On decreasing the bias percentage to $4.7 \%$, a broad asymmetric curve was observed. The optimum percentage bias was found to be $13 \%$ bias, because it gives a symmetrical peak of a considerable height.

\section{Concentration of supporting electrolyte}

To minimize the overpotential and improve the stability as well as the symmetry of the titration curve, the effect of changing the concentration of potassium nitrate used as a supporting electrolyte concentration was studied. It was found that at higher concentrations $(>1 \mathrm{M})$ the titration curve peak becomes broader, while at lower concentrations the height of the titration curve decreases. It was found that the best titration curve can be obtained if a $0.1 \mathrm{M}$ solution of $\mathrm{KNO}_{3}$ is used as can be seen in Fig. 5 .
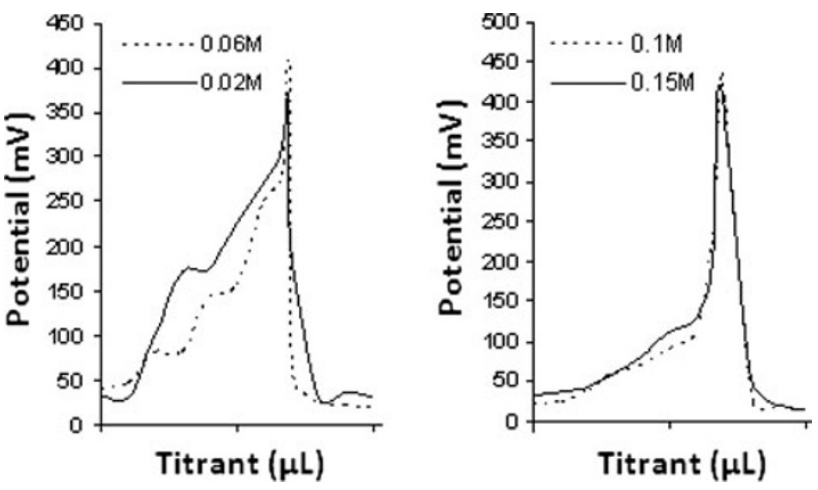

Fig. 5 Titration of $0.5 \mathrm{~mL}$ of $25 \mathrm{ppm}$ cyanide with $200 \mathrm{ppm}$ mercuric solution using gold amalgam electrodes. Current: $5 \mu \mathrm{A}$, in different concentrations of potassium nitrate, $0.02,0.06,0.1$ and $0.15 \mathrm{M}$
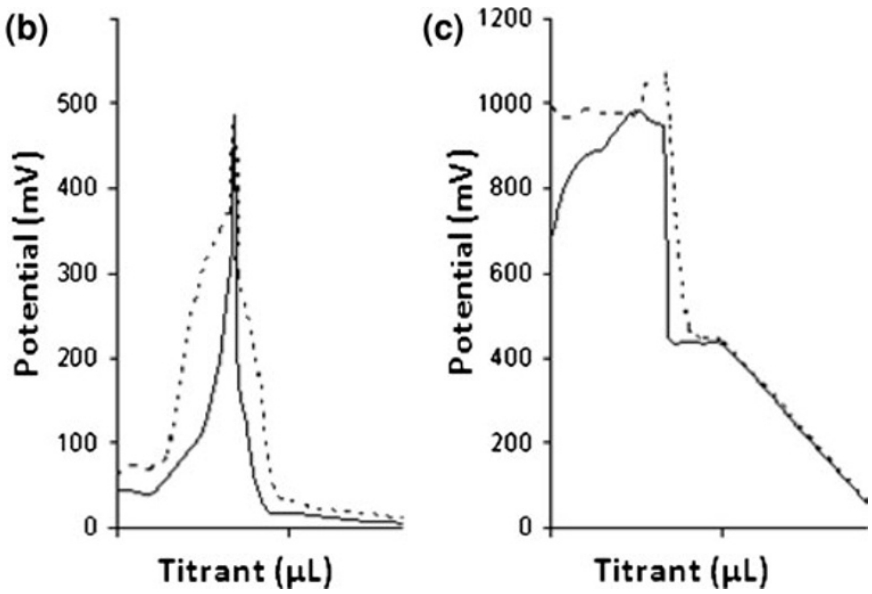

Calibration curve

Solutions of cyanide having different concentrations were titrated with mercuric nitrate. Figure 6 shows the titration curves obtained. The calibration curve was established with linearity between 0.20 and $25 \mathrm{ppm}$. Above $25 \mathrm{ppm}$, there was no linear response of the electrodes to different concentrations. Therefore, the linearity was difficult to be obtained in the range between $0.20 \mathrm{ppm}$ and concentrations higher than $25 \mathrm{ppm}$. Therefore, the linearity was selected in the range between 0.20 and $25 \mathrm{ppm}$. Calibration curve (or calibration equation) between end point and concentration of cyanide $y=0.0051 x+0.3669$ where y potential $(V)$ and $x$ is concentration (ppm) with $95 \%$ confidence level, $p=0.050$. The correlation coefficient was 0.9951 .

\section{Method evaluation}

The optimum sequential injection titration system was investigated for the effect of interferences, precision, and sample frequency. 

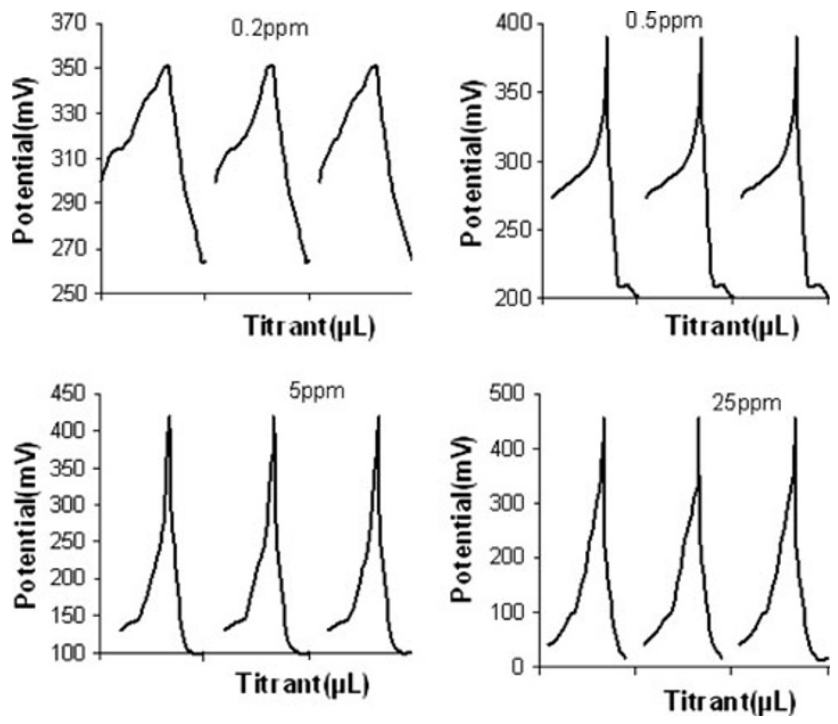

Fig. 6 Titration curves of $0.2,0.5,5$ and $25 \mathrm{ppm}$ cyanide at a dc current of $5 \mu \mathrm{A}$ and a $0.1 \mathrm{M} \mathrm{KNO}_{3}$ with $200 \mathrm{ppm} \mathrm{Hg}\left(\mathrm{NO}_{3}\right)_{2}$

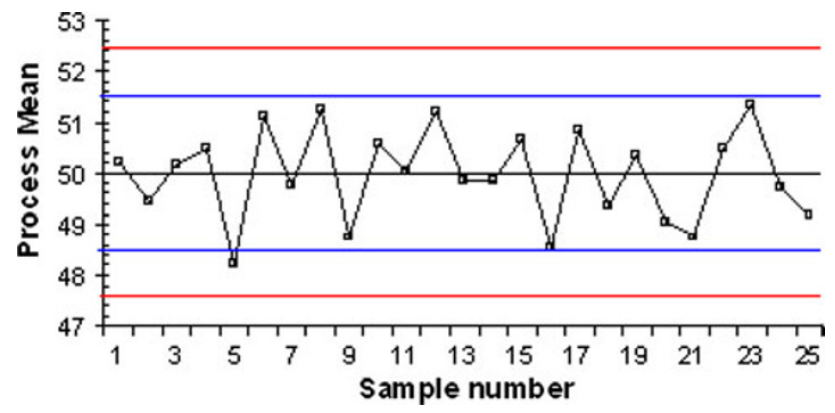

Fig. 7 Shewhart chart for mean values

\section{Precision}

The reproducibility and precision of the system was evaluated on five runs and repetitive determinations of representative samples under the selected optimum conditions using fixed cyanide ion concentration (50 ppm $\equiv$ $0.0012375 \mathrm{M})$. The percentage relative standard deviation (RSD) was found to be better than $1.43 \%$ ( $n=100)$. This indicates that the proposed system has good precision.

\section{Shewhart and Cusum control charts}

The optimum conditions of the previous mentioned optimized parameters were applied during the performance of these analyses. A standard solution of cyanide 50 ppm was analyzed in the laboratory for 25 consecutive days, the sample size being four on each cycle. Variability of signal generated in different days was drawn in a Shewhart (Miller and Miller 2000) control chart, Fig. 7. The cumulative sum of -0.9 was also statistically obtained as shown

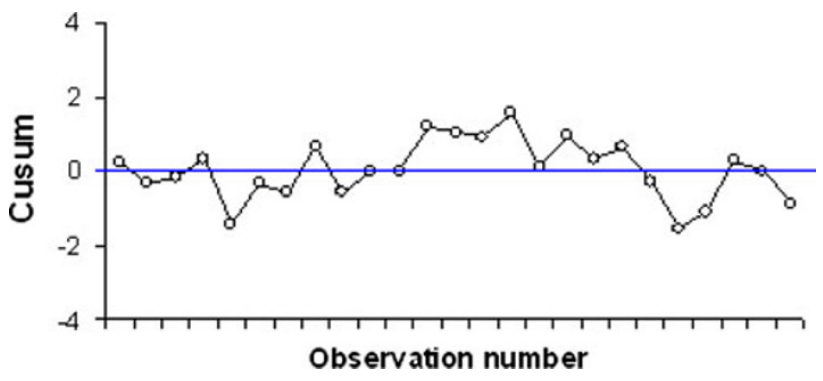

Fig. 8 Cumulative sum (Cusum) chart

Table 2 Effect of some foreign ions on the determination of $10 \mathrm{ppm}$ cyanide

\begin{tabular}{ll}
\hline $\begin{array}{l}\text { Interfering } \\
\text { ions }\end{array}$ & $\begin{array}{l}\text { Tolerated } \\
\text { concentration } \\
(\mathrm{ppm})\end{array}$ \\
\hline $\mathrm{Cl}^{-}$ & 350 \\
$\mathrm{I}^{-}$ & 300 \\
$\mathrm{PO}_{4}{ }^{3-}$ & 500 \\
$\mathrm{SO}_{4}{ }^{2-}$ & 150 \\
$\mathrm{Cu}^{2+}$ & 400 \\
$\mathrm{Au}^{+}$ & 200 \\
$\mathrm{Ag}^{+}$ & 350 \\
\hline
\end{tabular}

Deviation of $\pm 5 \%$ was allowed in the peak height

Table 3 Comparison of results with APHA standard method

\begin{tabular}{|c|c|c|c|c|}
\hline \multirow{3}{*}{$\begin{array}{l}\text { Cyanide added (spiked) into } \\
\text { real water samples (ppm) }\end{array}$} & \multicolumn{4}{|l|}{ Found } \\
\hline & \multicolumn{2}{|c|}{ SI titration } & \multicolumn{2}{|c|}{ Standard method } \\
\hline & $(\mathrm{ppm})$ & $\begin{array}{l}\text { Recovery } \\
\%\end{array}$ & (ppm) & $\begin{array}{l}\text { Recovery } \\
\%\end{array}$ \\
\hline 5 & 4.9 & 98.0 & 4.9 & 98.0 \\
\hline 20 & 20.4 & 102 & 20.5 & 102.5 \\
\hline 50 & 49.1 & 98.2 & 49.0 & 98.0 \\
\hline
\end{tabular}

Average of five determinations

in Fig. 8. These obtained statistical data reveal that the process is under control.

\section{Sample frequency}

On applying the optimum conditions, the proposed method was used for the determination of cyanide and a sampling rate of about 20 samples per hour was achieved.

\section{Interferences}

The effect of foreign anions on the reaction of mercuric nitrate with cyanide ion was studied at the optimum conditions using a fixed cyanide concentration $10 \mathrm{ppm}$ and varied concentrations of some foreign ions such as $\mathrm{Cl}^{-}, \mathrm{I}^{-}$, $\mathrm{PO}_{4}{ }^{3-}$, and $\mathrm{SO}_{4}{ }^{2-}$. Table 2 summarizes the tolerance 
limits of tested foreign ions. In addition, it was found that $\mathrm{Cu}^{2+}, \mathrm{Ag}^{+}$and $\mathrm{Au}^{+}$pose less interference. The stability constants of which are lower $\left(21.7,20.4\right.$ and $\left.36.6 \beta_{2}\right)$ than that of mercuric-cyanide complex, 38.3 (Erik 1982). The interference of $\mathrm{SO}_{4}^{-2}$ ion can be circumvented through acid distillation of the cyanide ions solution.

Comparisons of results with the standard method

The comparison between the proposed method and the standard method was performed by real sample analysis. The results obtained using the proposed sequential titration method was statically evaluated and compared with the standard method, American public health association (APHA) (Clesceri et al. 1995). The results show good agreement, Table 3. The calculated $t$ value was 0.783 which is less than the tabulated $t, 2.78$ ( $p=0.05,95 \%$ confidence level). In addition, it was found that $F$ value is 1.713 that is less than the tabulated value, 3.708. In addition the cumulative sum was -0.9 .

\section{Conclusion}

The proposed SI titration method is simple, rapid, inexpensive in terms of instrumentation cost, reagent and sample consumption, and manpower. It has a good reproducibility with about 20 samples per hour sampling rate. The sensitivity of the proposed method is greatly enhanced by the use of m.s.b. current source for polarizing goldamalgam electrodes. The statistical analysis indicates that $t$ value was $0.783, F$ value was 1.713 , and relative recovery was $98-102 \%$. We here based on our findings recommend the equipments to be compact in one unit and used as a portable method for in situ detection of cyanide. A simple column for cyanide separation can be involved as well to get rid of the interferences.

Acknowledgments The authors acknowledge the financial support of King Abdulaziz city for Science and Technology (KACST) under project APR -26-72.The support of Chemistry department at King Fahd University of Petroleum and Minerals is also acknowledged.
Open Access This article is distributed under the terms of the Creative Commons Attribution License which permits any use, distribution and reproduction in any medium, provided the original author(s) and source are credited.

\section{References}

Abulkibash AM, Koken ME, Khaled MM, Sultan SM (2000) Differential electrolytic potentiometry, a detector in flow injection analysis for oxidation-reduction reactions. Talanta 52:1139-1142

Abulkibash AM, Sultan SM, Al-Olyan AM, Al-Ghannam SM (2003) Differential electrolytic potentiometric titration method for the determination of ciprofloxacin in drug formulations. Talanta 61:239-244

Al-Ghannam SM (2004) Differential electrolytic potentiometric determination of some thiol compounds in their dosage forms. Farmaco Societa chimica italiana 59(4):331-334

Clesceri LS, Greenberg AE, Eaton AD (1995) Standard methods for the examination of water and wastewater, 19th edn. American Public Health Association, Washington. http://www.standardmethods.org/

Erik H (1982) Stability constants of metal-ion complexes. Part A. Inorganic ligands, 1st edn. Stockholm, Sweden

Johnson DC, LaCours WR (1990) Liquid chromatography with pulsed electrochemical detection at gold and platinum electrodes. Anal Chem 62(10):589A-597A

Lukey GC, Deventer JSJ, Huntington ST, Chowdhury RL, Shallcross DC (1999) Raman study on the speciation of copper cyanide complexes in highly saline solutions. Hydrometallurgy 53(3): 233-244

MacArthur JS, Forrest RW, Forrest W (1988) Improvements in obtaining gold and silver from ores and other compounds. British Patent No. 14174

Miller JN, Miller JC (2000) Statistical and chemometrics for analytical chemistry, 4th edn., pp 76-91

Schnepp R (2006) Cyanide: sources, perceptions, and risks. J Emerg Nursing 32:S3-S7

Stankovic SM, Jovanović MS, Jovanović VM, Djikanović M (1993) Application of glassy carbon substrated cyanide-sensitive electrodes in determination of cyanide and mercaptan levels of wastewater. Electroanalysis 5:703-707

Stuart AD, Van der Heuvel R (1992) Assessment of infrared spectroscopy for detecting cyanide species in aqueous solutions. Int J Environ Anal Chem 49 (3):171-181

Themelis DG, Karastogianni SC, Tzanavaras PD (2009) Selective determination of cyanides by gas diffusion-stopped flow-sequential injection analysis and an on-line standard addition approach. Anal Chim Acta 632:93-100 